\title{
Stereoselective Total Synthesis of (-)-Renieramycin T
}

Masashi Yokoya, ${ }^{*} \uparrow$ Ryoko Toyoshima, $\uparrow$ Toshihiro Suzuki, $\uparrow$ Vy H. Le, + Robert M. Williams, ${ }^{*}+$ and Naoki

Saito $†$

†Graduate School of Pharmaceutical Sciences, Meiji Pharmaceutical University, 2-522-1 Noshio, Kiyose, Tokyo 204-

8588, Japan

†Department of Chemistry Colorado State University Fort Collins, Colorado 80523 and The $\$$ University of Colorado

Cancer Center, Aurora, Colorado 80045

*yokoya@my-pharm.ac.jp

*robert.williams@,colostate.edu

Supporting Information

NMR data 


\section{Table of Contents}

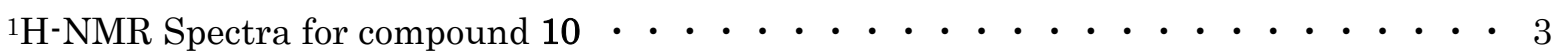

${ }^{1} \mathrm{H}^{-}$and ${ }^{13} \mathrm{C}-\mathrm{NMR}$ Spectra for compound $11 \ldots \ldots$

${ }^{1} \mathrm{H}$-NMR Spectra for compound $14 . \cdots \cdot \ldots$

${ }^{1} \mathrm{H}-\mathrm{NMR}$ Spectra for compound $15 \cdot \cdots \cdot \cdots \cdot \cdots \cdot \cdots$

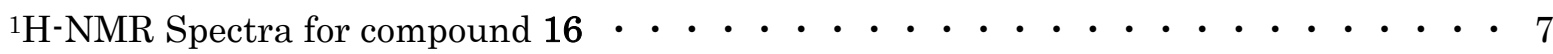

${ }^{1} \mathrm{H}^{-}$and ${ }^{13} \mathrm{C}-\mathrm{NMR}$ Spectra for compound $18 \cdot \cdots \cdot \cdots \cdot \cdots \cdot \cdots$

${ }^{1} \mathrm{H}^{-}$and ${ }^{13} \mathrm{C}-\mathrm{NMR}$ Spectra for compound $19 \cdots \cdots$

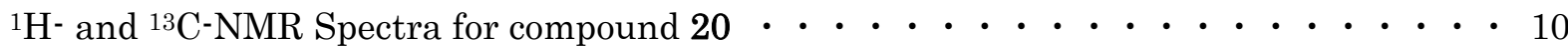

${ }^{1} \mathrm{H}^{-}$and ${ }^{13} \mathrm{C}-\mathrm{NMR}$ Spectra for compound $21 \mathrm{a} \cdot \cdots \cdot \cdots$

${ }^{1} \mathrm{H}^{-}$and ${ }^{13} \mathrm{C}-\mathrm{NMR}$ Spectra for compound $22 \ldots \ldots \ldots$

${ }^{1} \mathrm{H}^{-}$and ${ }^{13} \mathrm{C}-\mathrm{NMR}$ Spectra for compound $23 \cdots \cdots \cdots \cdots$

${ }^{1} \mathrm{H}^{-}$and ${ }^{13} \mathrm{C}-\mathrm{NMR}$ Spectra for compound $24 \mathrm{a} \ldots \ldots \ldots$

${ }^{1} \mathrm{H}^{-}$and ${ }^{13} \mathrm{C}-\mathrm{NMR}$ Spectra for compound $24 \mathrm{~b} \cdot \ldots \ldots$

${ }^{1} \mathrm{H}^{-}$and ${ }^{13} \mathrm{C}-\mathrm{NMR}$ Spectra for compound $25 \ldots \ldots \ldots$

${ }^{1} \mathrm{H}^{-}$and ${ }^{13} \mathrm{C}-\mathrm{NMR}$ Spectra for compound $26 \cdots \cdots \cdots$

${ }^{1} \mathrm{H}^{-}$and ${ }^{13} \mathrm{C}-\mathrm{NMR}$ Spectra for compound renieramycin $\mathrm{T}(\mathrm{1t})[$ synthetic] $\cdots \cdots \cdots$

${ }^{1} \mathrm{H}^{-}$and ${ }^{13} \mathrm{C}-\mathrm{NMR}$ Spectra for compound renieramycin $\mathrm{T}(1 \mathrm{t})$ [natural $] \cdot \cdots \cdot \cdots$ 

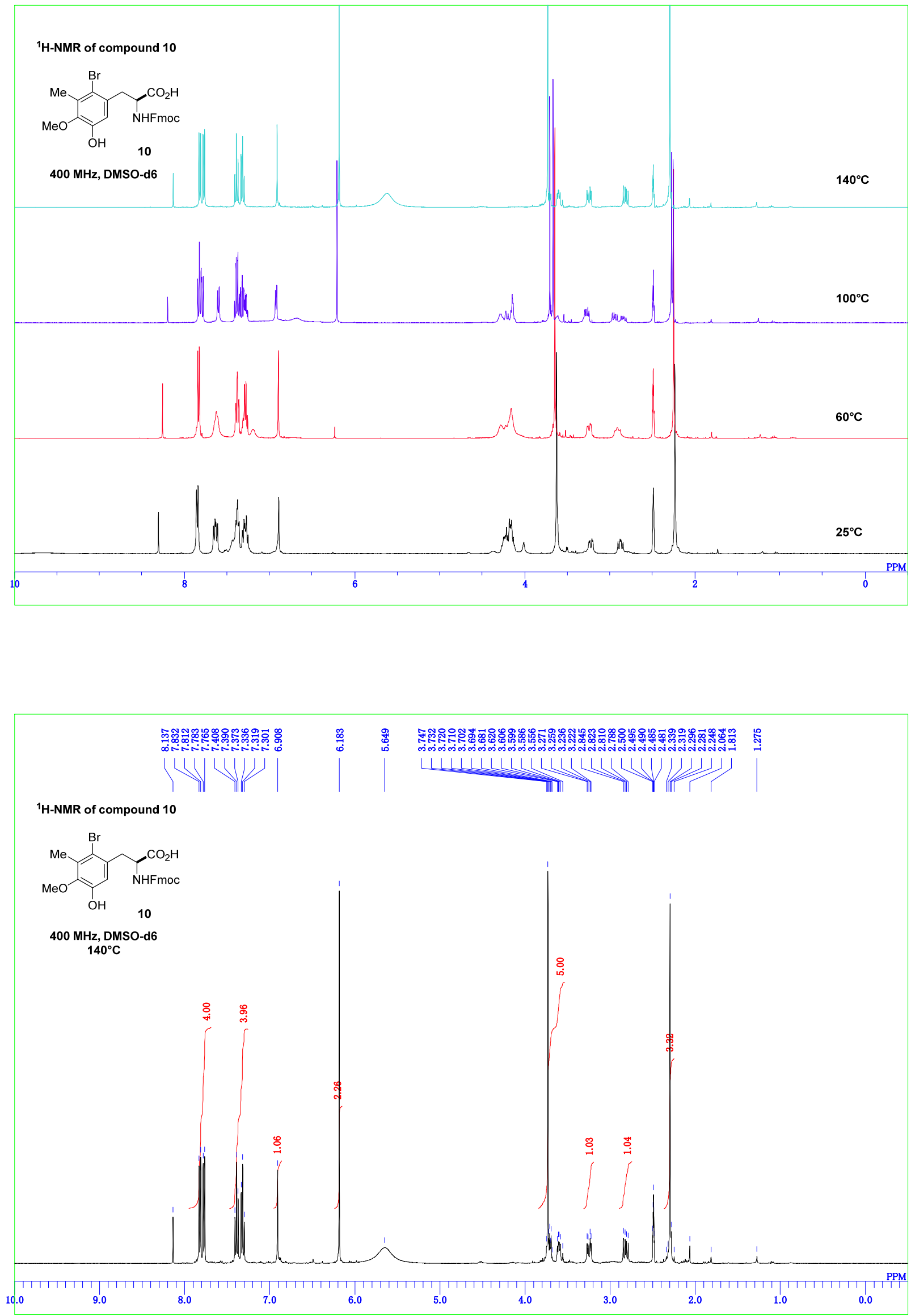

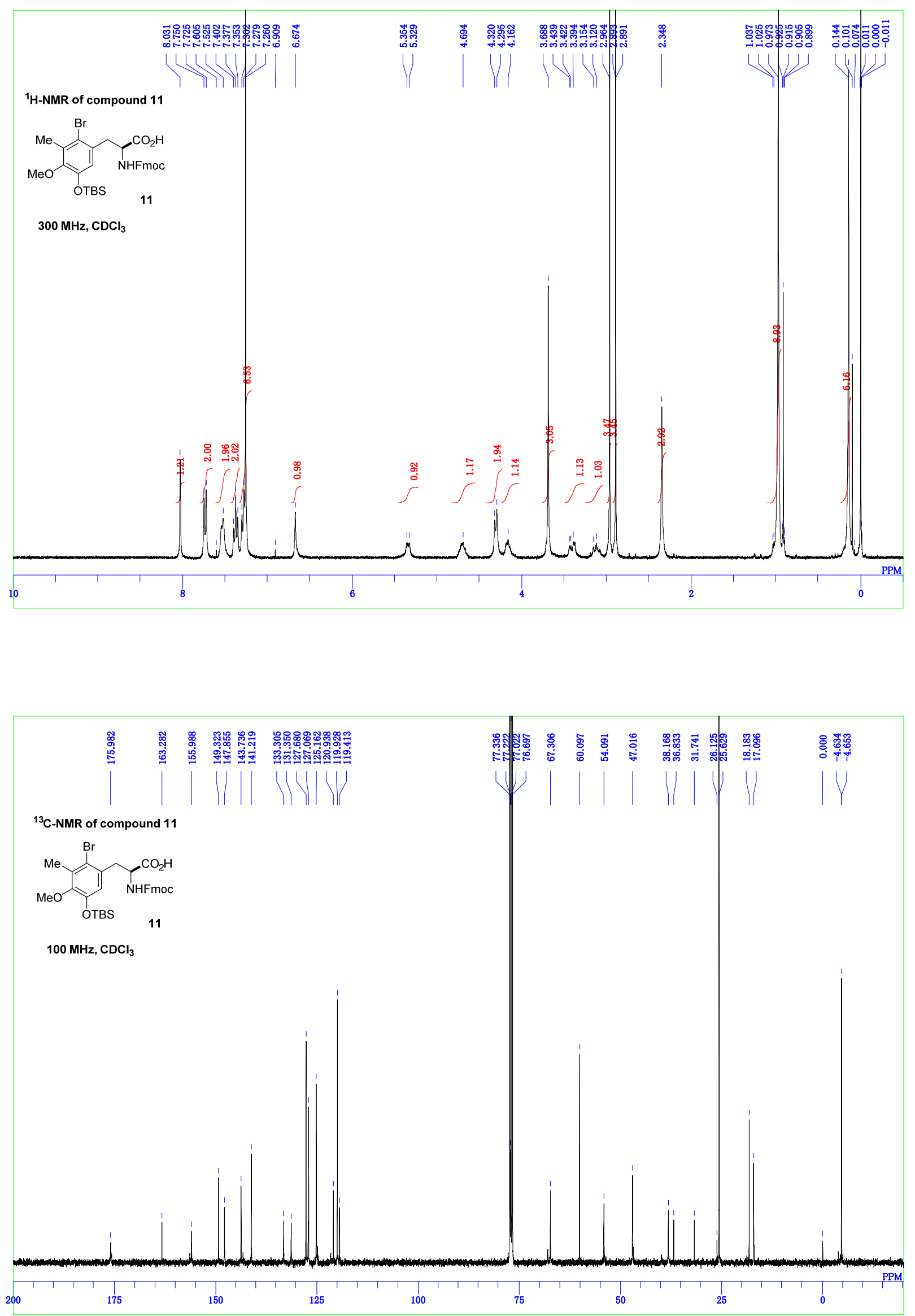

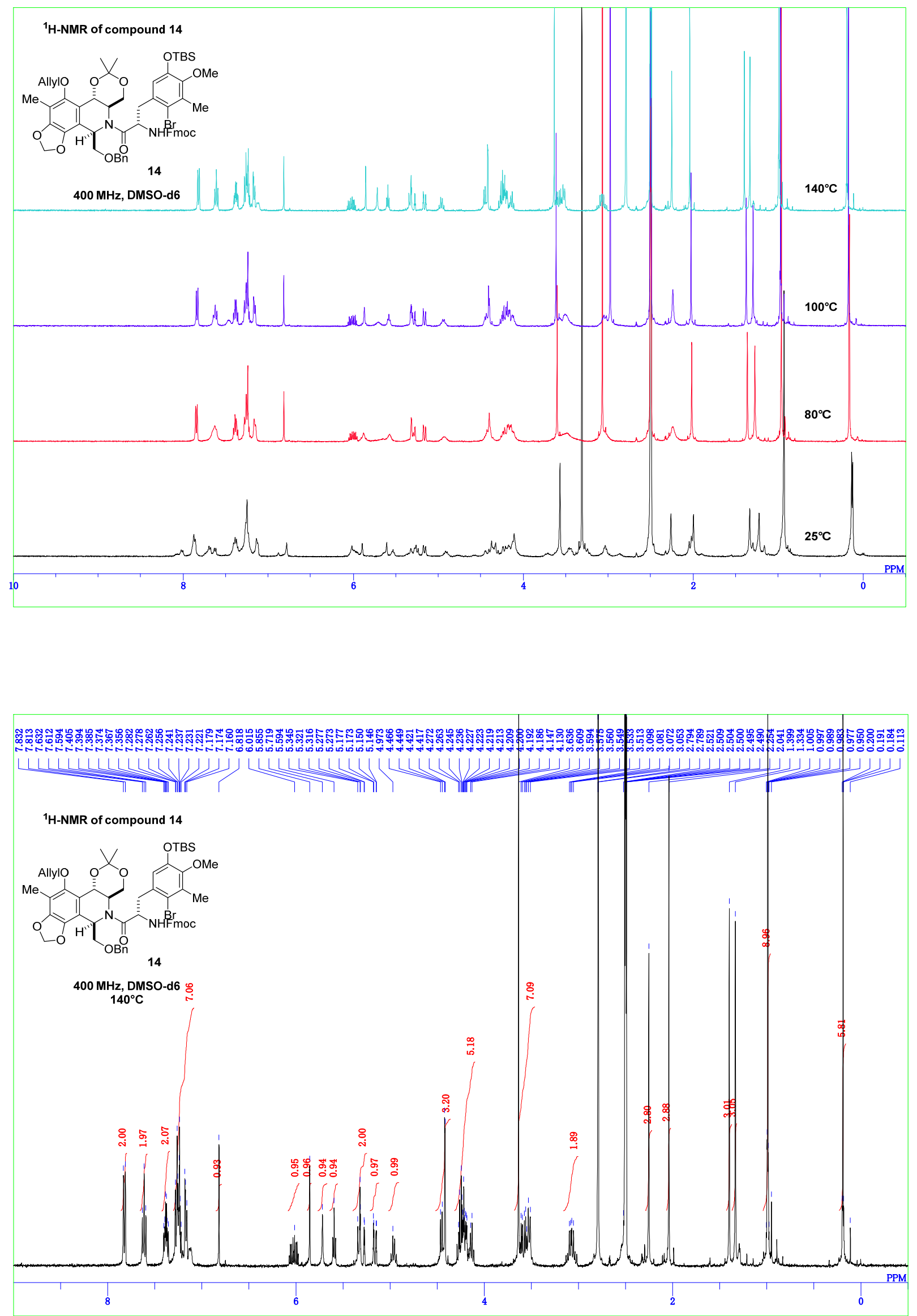

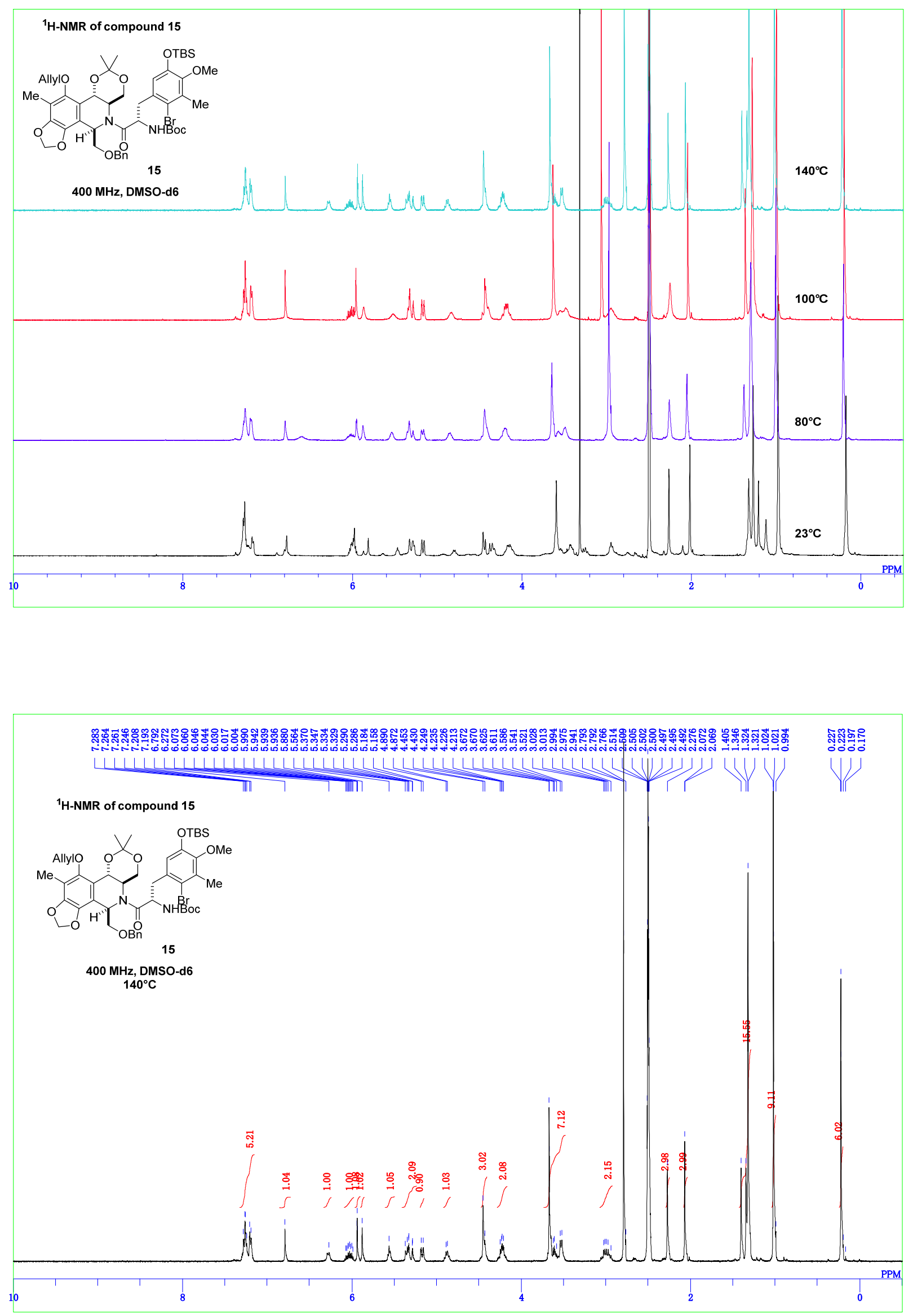

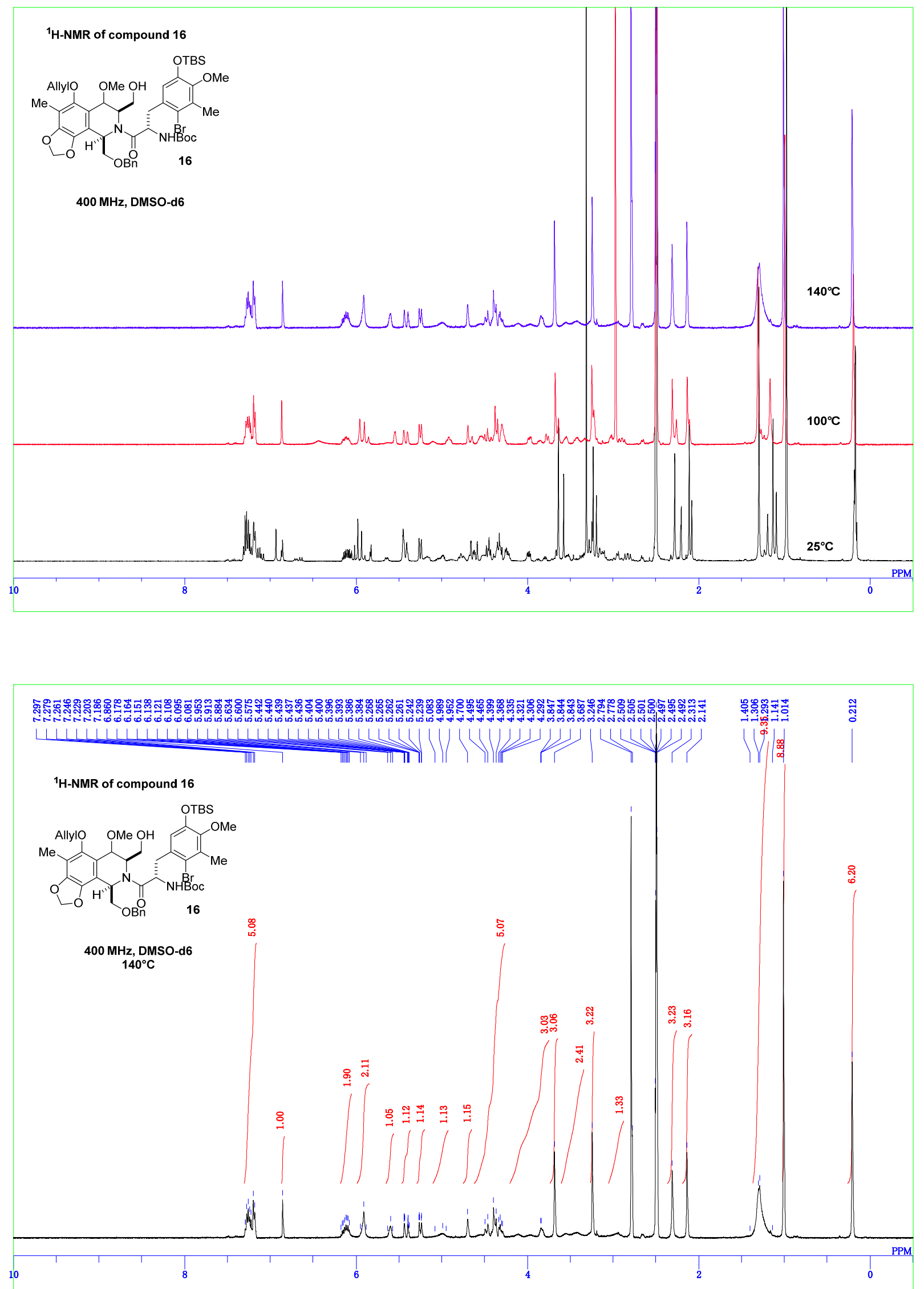

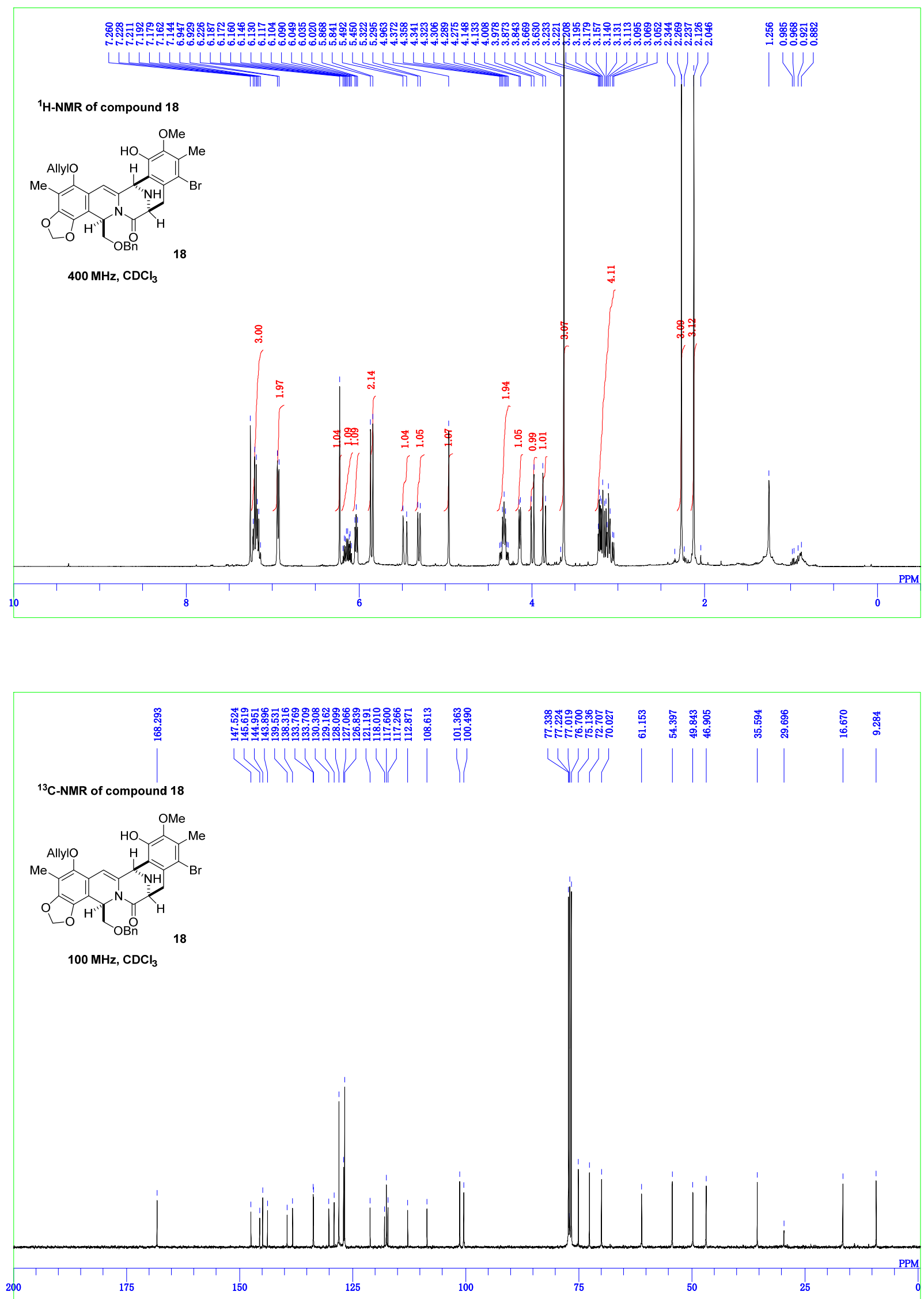

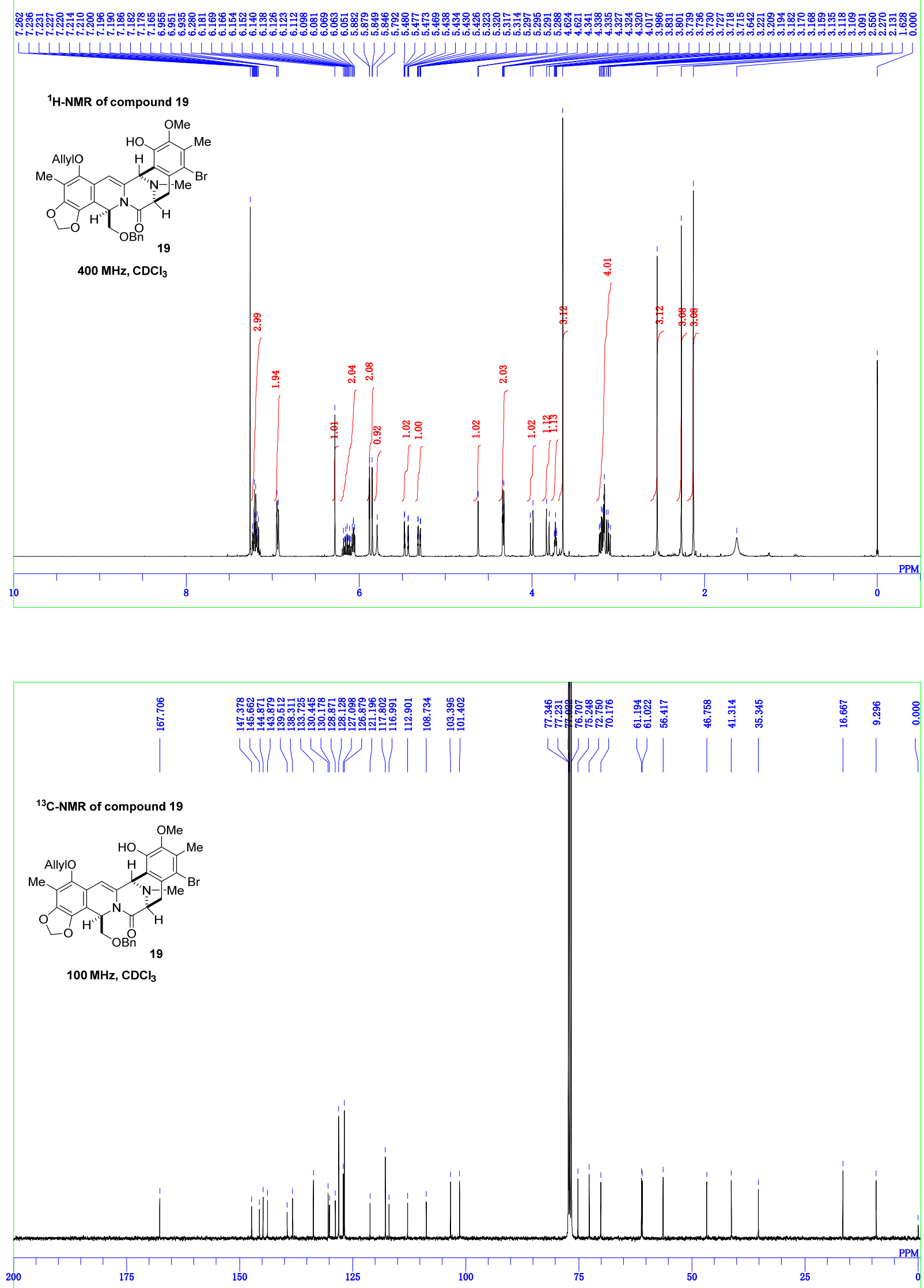

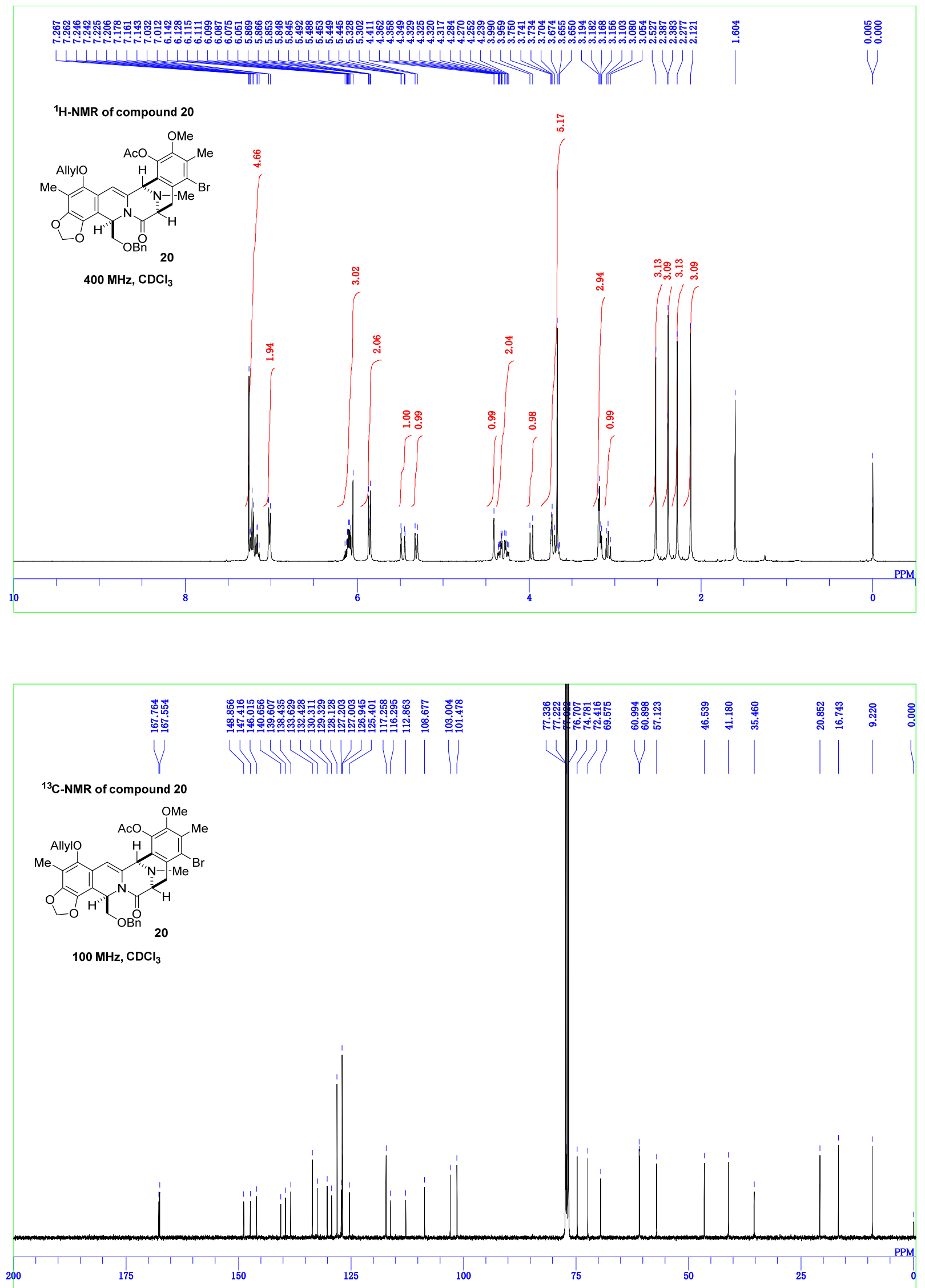

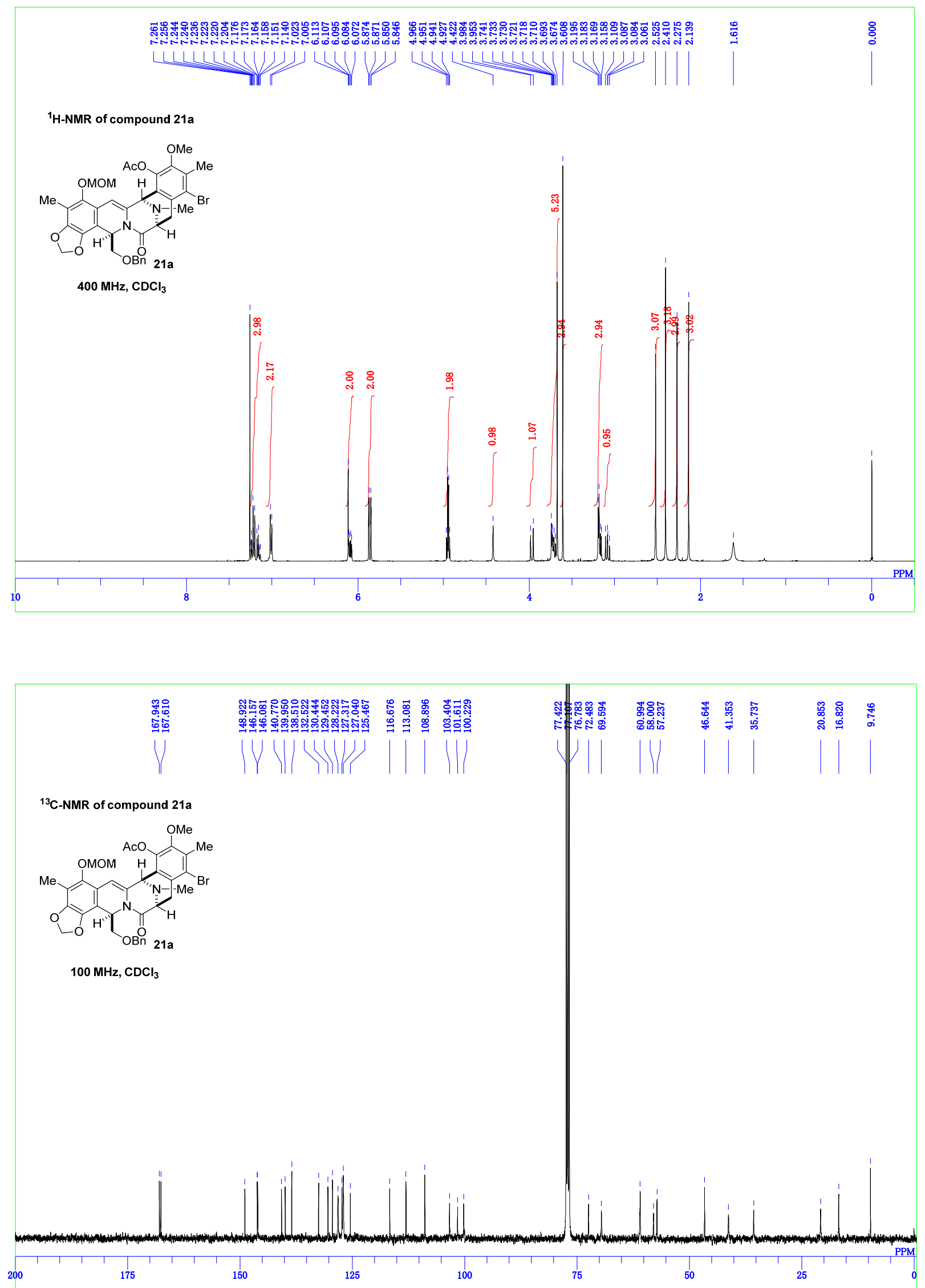

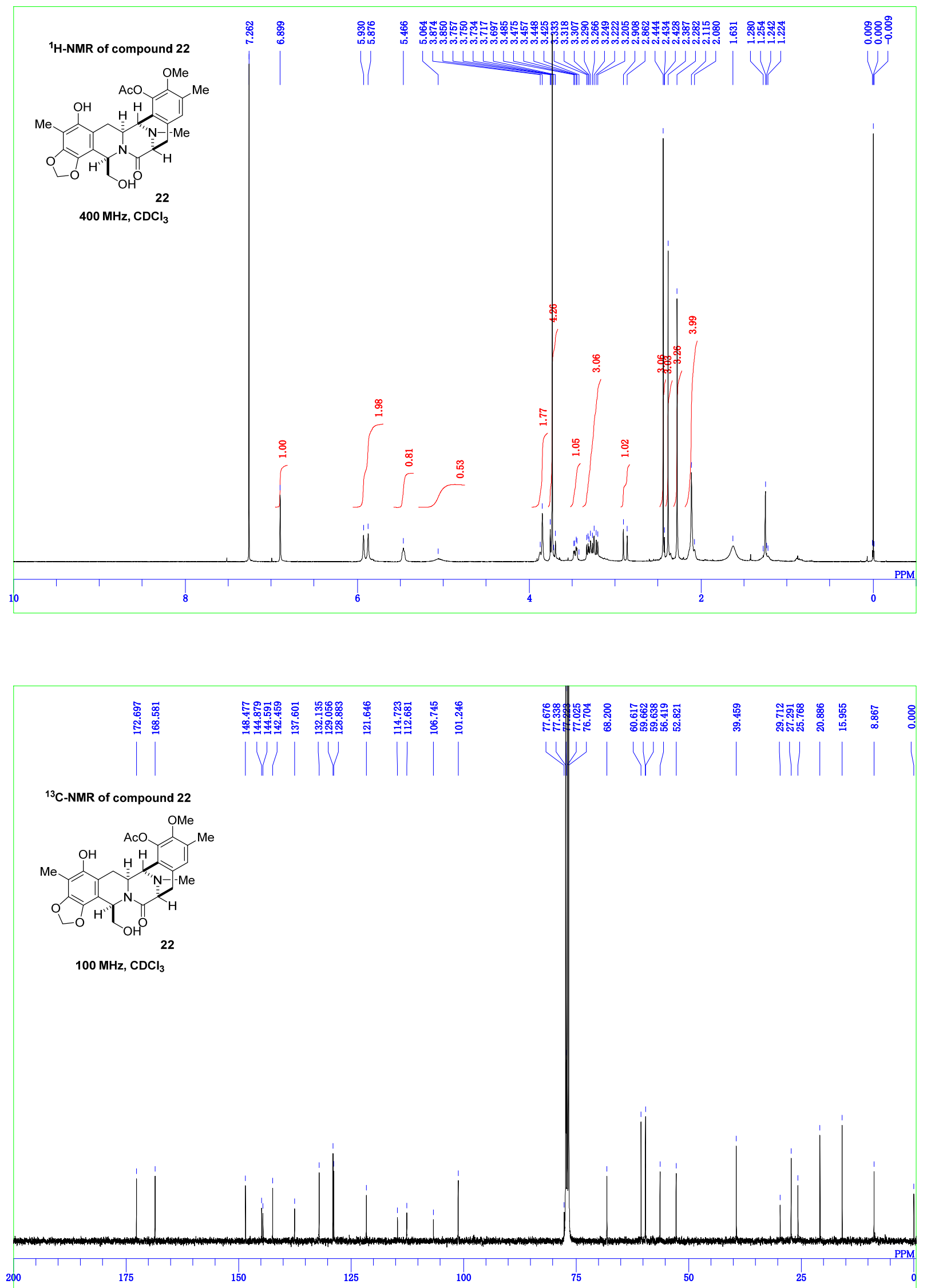

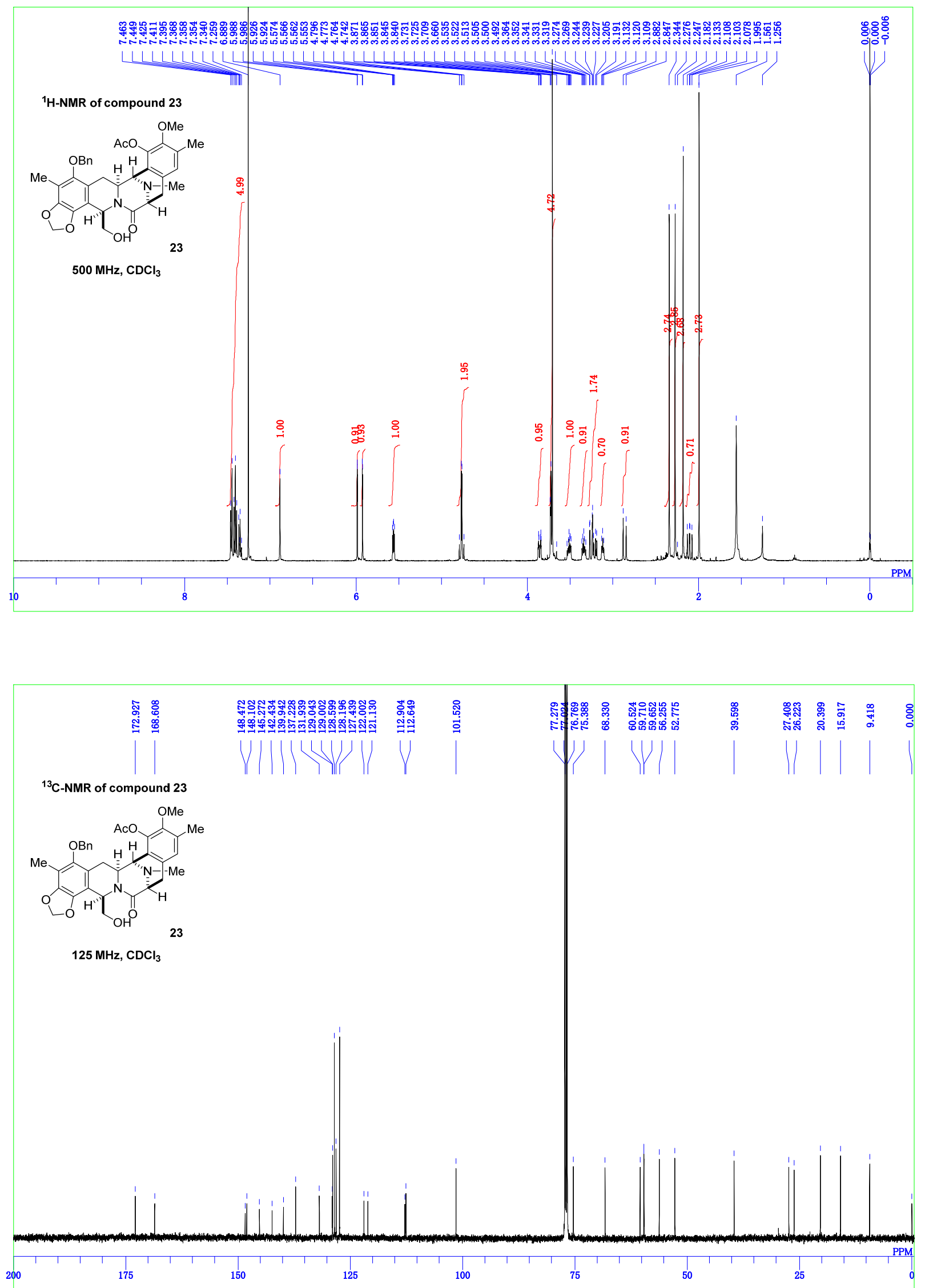

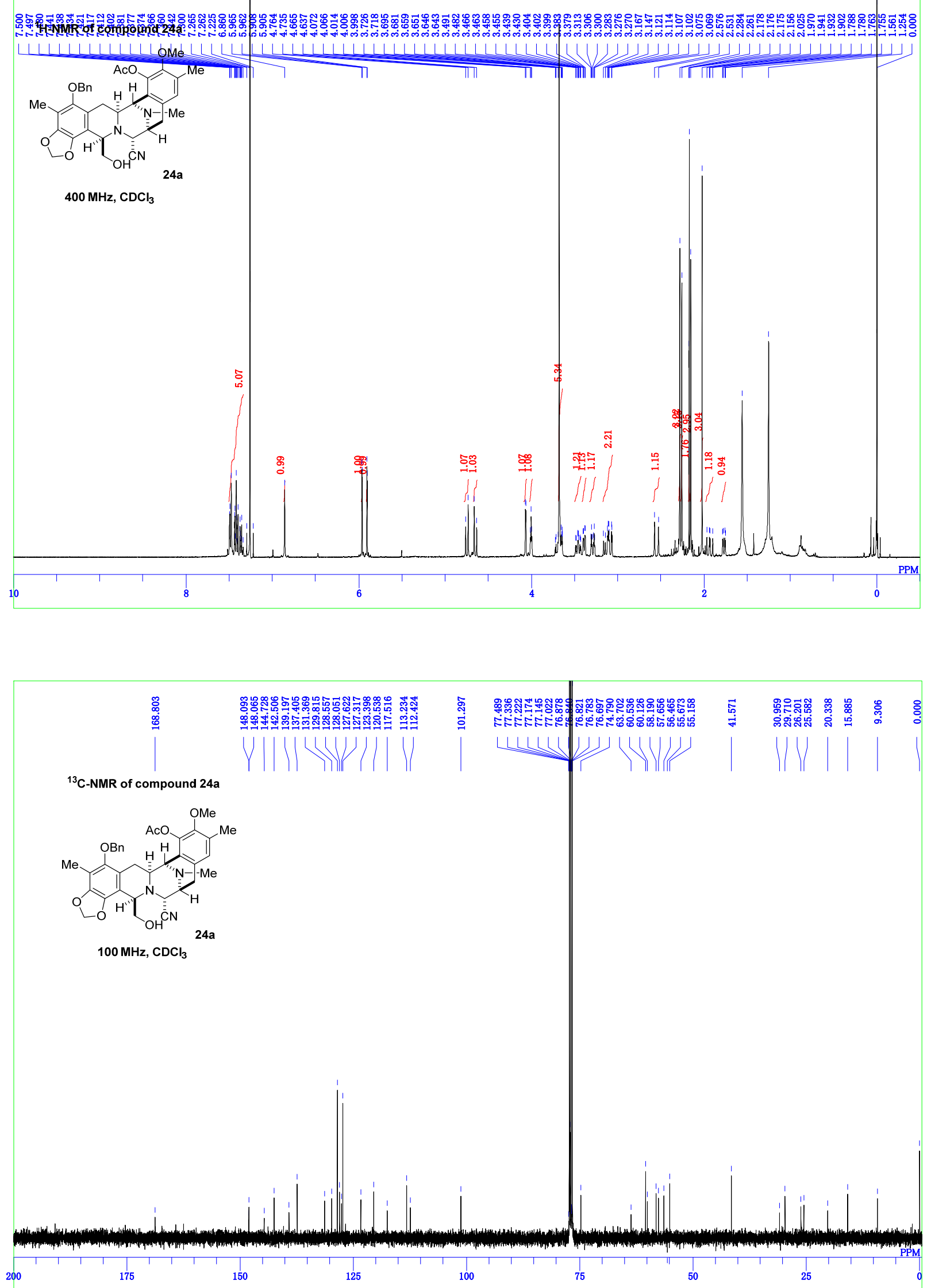

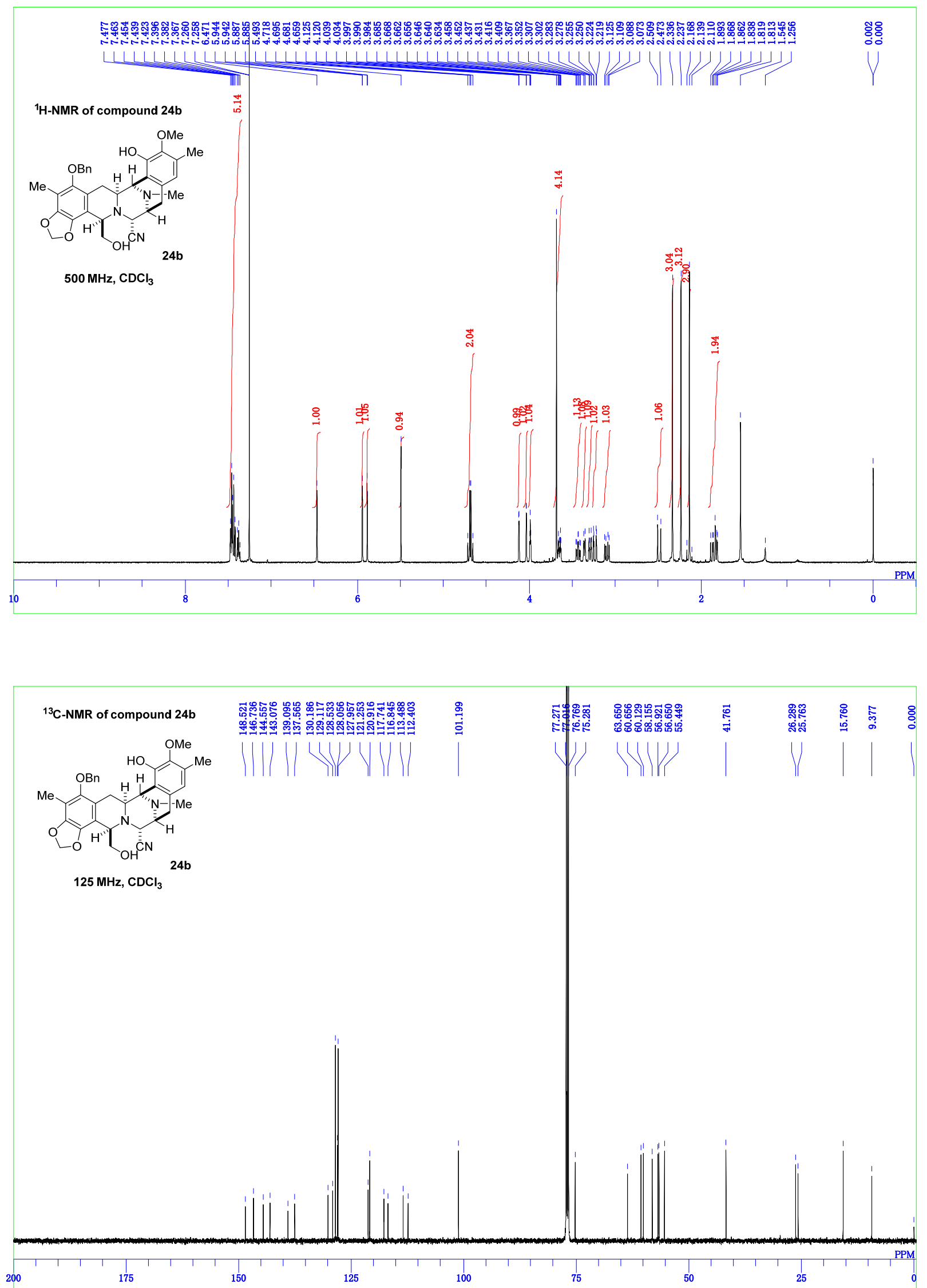

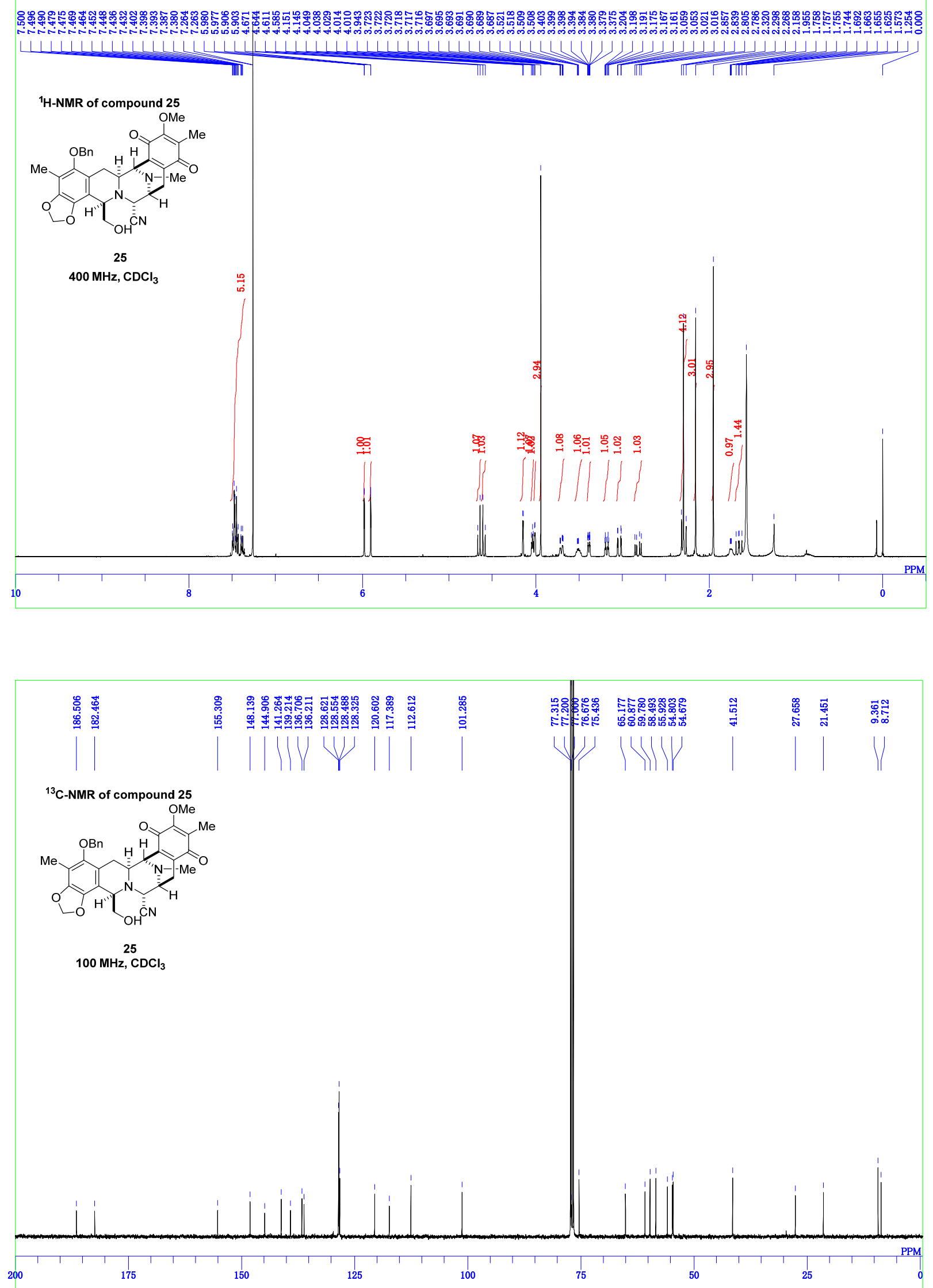

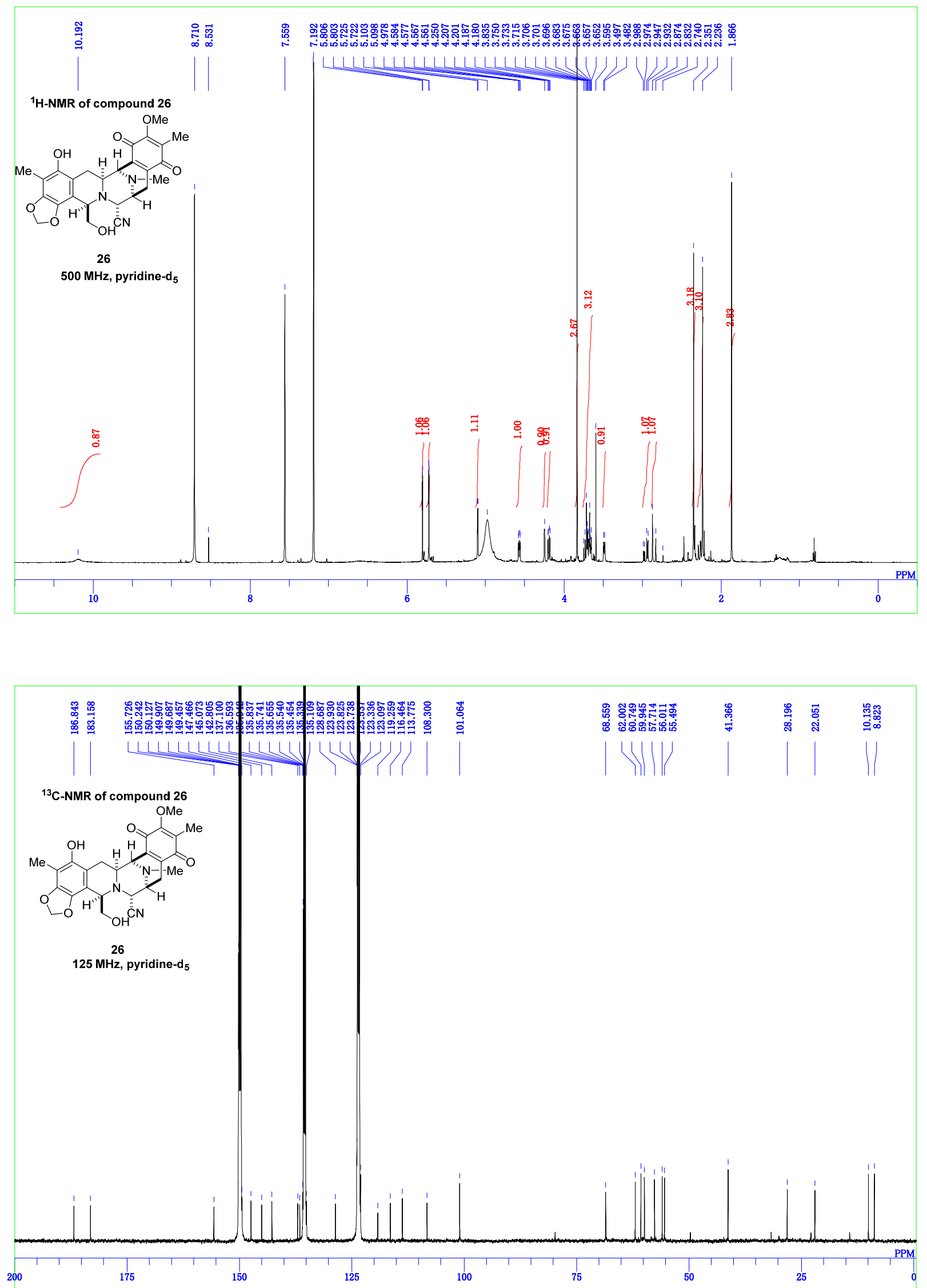

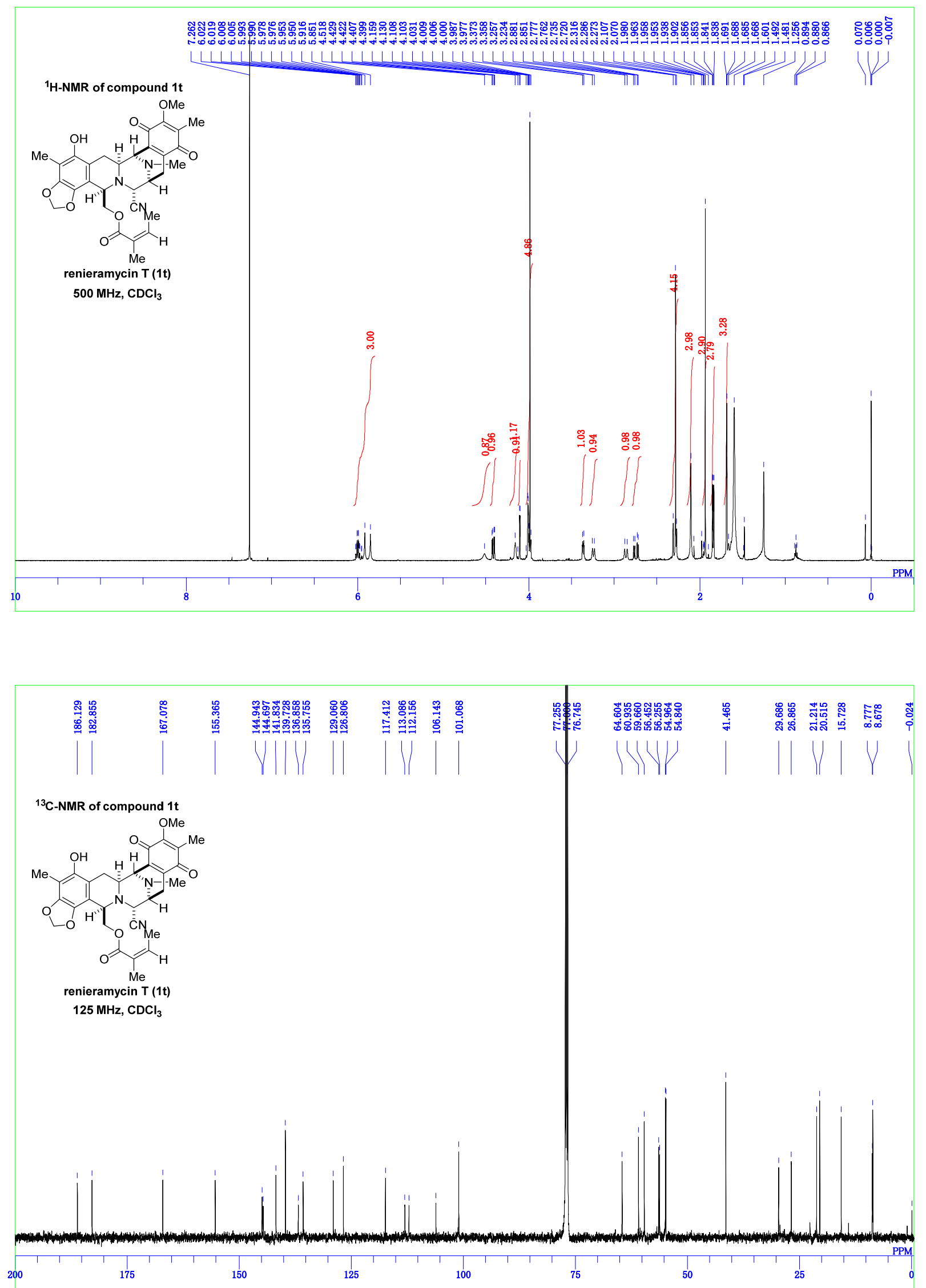

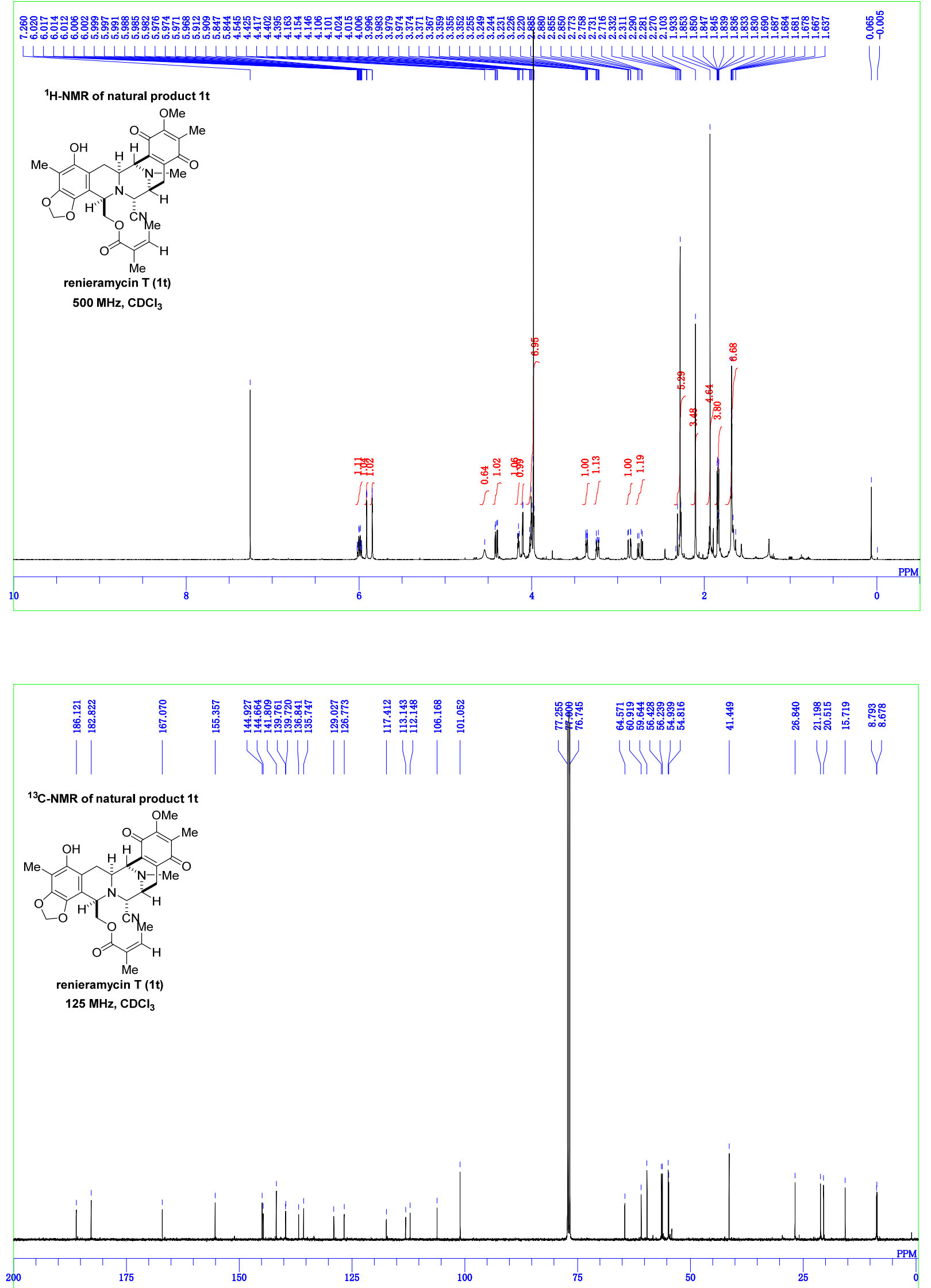